\title{
Types of inferior phrenic arteries: a new point of view based on a cadaveric study
}

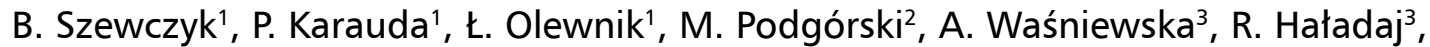 \\ E. Rapacka ${ }^{3}$, P. Oszukowski ${ }^{4}$, M. Polguj ${ }^{3}$ \\ ${ }^{1}$ Department of Anatomical Dissection and Donation, Medical University of Lodz, Poland \\ ${ }^{2}$ Department of Diagnostic Imaging of Polish Mother's Memorial Hospital Research Institute, Lodz, Poland \\ ${ }^{3}$ Department of Normal and Clinical Anatomy, Chair of Anatomy and Histology, Medical University of Lodz, Poland \\ ${ }^{4}$ Department of Clinical Morphology, Medical University of Lodz, Poland
}

[Received: 23 April 2020; Accepted: 22 June 2020; Early publication date: 21 July 2020]

Background: The diaphragm is supplied by the superior and inferior phrenic arteries. This present study focusses on the latter. The inferior phrenic arteries (IPA) usually originate from the abdominal aorta. The two arteries have different origins, and knowledge of these is important when performing related surgical interventions and interventional radiological procedures. The aim of this study was to identify variations in the origin of the IPA and conduct relevant morphometric analyses.

Materials and methods: The anatomical variations in the origins of the left inferior phrenic artery (LIPA) and the right inferior phrenic artery (RIPA) were examined in 48 cadavers fixed in 10\% formalin solution. A dissection of the abdominal region of the cadavers was performed according to a pre-established protocol using traditional techniques. Morphometric measurements were then taken twice by two of the researchers. Results: In the cadavers, six types of origin were observed. In type 1, the most common type, the RIPA and LIPA originate from the abdominal aorta (AA) $(14=29.12 \%)$. In type 2 , the RIPA and the LIPA originate from the coeliac trunk (CT) $(12=24.96 \%)$. In type 3, the RIPA and the LIPA originate from the left gastric artery, with no CT observed $(3=6.24 \%)$. Type 4 has two subtypes: $4 A$, in which the LIPA originates from the $A A$ and the RIPA originates from the CT $(9=18.72 \%)$ and $4 B$, in which the RIPA originates from the $A A$ and the LIPA originates from the $C T(6=12.48 \%)$. In type 5 , the LIPA originates from the AA and the RIPA originates from the $A A(1=2.08 \%)$. Type 6 is characterised by the RIPA and LIPA forming a common trunk originating from the CT $(3=6.24 \%)$.

Conclusions: Our findings suggest the presence of six different types of LIPA and RIPA origin. The most common form is type 1, characterised by an IPA originating from the abdominal aorta, while the second most common is type 2, in which the IPA originates from the AA by a common trunk. The diversity of other types of origin is associated with the occurrence of coeliac trunk variation (type 3). No significant differences in RIPA diameter could be found, whereas LIPA diameter could vary significantly. No significant differences in RIPA and the LIPA diameter could be found according to sex. (Folia Morphol 2021; 80, 3: 567-574)

Key words: inferior phrenic arteries, left inferior phrenic artery, right inferior phrenic artery, diaphragm, coeliac trunk

Address for correspondence: Ass. B. Szewczyk, Department of Anatomical Dissection and Donation, Medical University of Lodz, ul. Żeligowskiego 7/9, 90-752 Łódź, Poland, tel: +48 4263049 49, +48 4263007 49, e-mail: bartlomiej.szewczyk@umed.lodz.pl; Dr. Ł. Olewnik; Department of Normal and Clinical Anatomy University of Łódź, ul. Żeligowskiego 7/9, 90-752 Łódź, Poland, tel: +48 4263049 49, +48 4263007 49, e-mail: lukasz.olewnik@umed.lodz.pl

This article is available in open access under Creative Common Attribution-Non-Commercial-No Derivatives 4.0 International (CC BY-NC-ND 4.0) license, allowing to download articles and share them with others as long as they credit the authors and the publisher, but without permission to change them in any way or use them commercially. 


\section{INTRODUCTION}

The inferior phrenic artery (IPA) usually originates from the abdominal aorta (AA) and consists of two vessels, i.e. the left inferior phrenic artery (LIPA) and the right inferior phrenic artery (RIPA). The two give rise to the ascending (anterior) and the descending (posterior) branches. Although the IPA mainly supplies the diaphragm, it also gives small branches to the liver, stomach, the cardiac part of the oesophagus, the adrenal glands, and retroperitoneum $[1,4,36]$.

The anterior branch of the LIPA gives rise to the oesophageal and accessory splenic branches while the RIPA rises along with inferior vena cava [1, 36]. However, the posterior branches of both IPAs run to the lateral crus and can form anastomoses with the musculophrenic artery and the lower posterior intercostal arteries $[7,29,31]$.

The LIPA usually runs behind the oesophagus, and goes anteriorly to the left side of the oesophageal hiatus. The ascending branch divides into two trunks: the larger anterior and the smaller posterior. The anterior trunk directly supplies the area of the oesophagogastric junction and the dome of the diaphragm [9]. Additionally, a small number of branches may also attach to the superior pole of the spleen $[2,6,18,30]$.

The RIPA usually passes behind the left hepatic lobe and the inferior vena cava $[25,35]$. The ascending branch is usually located cranially and contacts the bare area of the liver $[29,36]$.

In most cases, the LIPA and RIPA arise separately from the $A A$ above the origin of the coeliac trunk (CT) $[25,30,36]$; however, they may demonstrate various types of origin [13,20,23,35]. Information on the possible position of this artery can be valuable for understanding and treating the source of arterial bleeding at the oesophagogastric junction $[9,39]$.

The most commonly recognized clinical feature of the RIPA is that it may serve as an extrahepatic collateral arterial supply route to hepatocellular carcinomas $[3,34]$. This is important information for surgeons since, in such a case, transcatheter embolisation of RIPA may help in the treatment of unresectable hepatocellular carcinoma $[3,16,34]$.

This vessel is one of the main sources of postoperative bleeding in liver transplant recipients. In living donors undergoing right hepatic lobectomy, ligation of the artery is necessary for the donor and for hepatectomy in the recipient [17].
However, previous studies have so far examined each of the arteries separately and none have proposed any classifications. Therefore, the aim of our study was to investigate the anatomy of IPA types by classical anatomical dissection, and to propose a classification based on the origin of both the RIPA and LIPA.

\section{MATERIALS AND METHODS}

\section{Anatomical studies}

The study was performed on upper abdominal region of 48 adult Caucasian cadavers (29 males and 19 females) that had been fixed in $10 \%$ formalin solution before examination. The cadavers were the property of the Department, having been donated to the university anatomy programme. Cadavers with any evidence of surgical intervention in the dissected area were excluded from the study.

\section{Description of the dissection protocol}

Firstly, the abdominal cavity was opened by making incisions along the linea alba from the xiphoid process to the pubic symphysis. Next, after making sure there was no evidence of trauma, pathology or prior surgery in the upper abdominal organs, the origin of the RIPA and LIPA was recorded

Upon dissection, the morphological features of the IPA were assessed:

- origin of the LIPA and the RIPA;

- diameter of the LIPA (measurement taken at the origin);

- diameter of the RIPA (measurement taken at the origin).

All measurements were performed using an electronic digital calliper gauge (Mitutoyo Corporation, Kawasaki-shi, Kanagawa, Japan). Each measurement was carried out twice with an accuracy of up to $0.1 \mathrm{~mm}$. The consent for the anatomical studies was obtained from the Local Bioethical Commission RNN/404/19/KE

\section{Statistical analysis}

In the statistical analysis, IPA types were compared according to genders and sides with the $\chi^{2}$ test. The normality of the morphometric data distribution was checked with the Shapiro-Wilk test. As the data was not normally distributed, the Mann-Whitney test and the Wilocoxon sign-rank test were used to compare anthropometric measurements between the sexes and sides, respectively. Differences in morphometric 


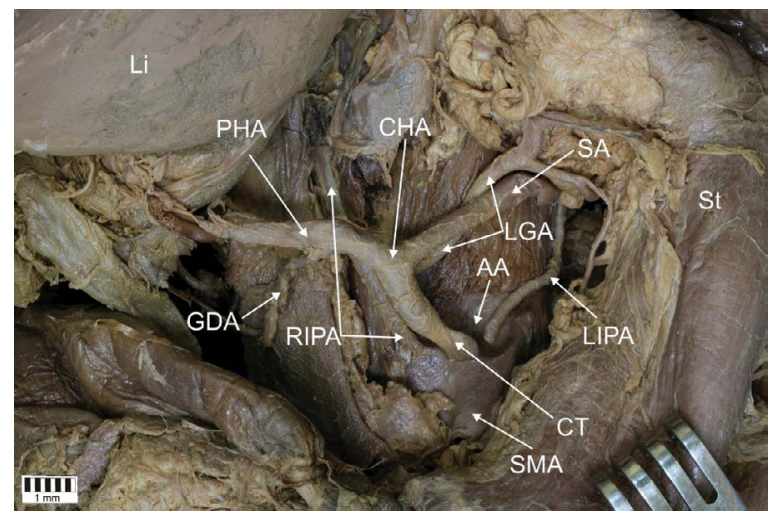

Figure 1. Type $1-$ the RIPA and LIPA originate from the abdominal aorta. PHA — proper hepatic artery; GDA — gastro-duodenal artery; RIPA — right inferior phrenic artery; $\mathrm{CHA}$ - common hepatic artery; LGA — left gastric artery; SA — splenic artery; LIPA — left inferior phrenic artery; CT — coeliac trunk; SMA - superior mesentery artery; $\mathrm{St}$ — stomach; $\mathrm{Li}$ - liver; AA — abdominal aorta.

measurements between the types were assessed with the Kruskal-Wallis ANOVA with a dedicated post hoc test. Statistica 13 software (StatSoft Polska, Krakow, Poland) was used for the analysis and a p-value lower than 0.05 was considered significant. The results are presented as mean and standard deviation unless stated otherwise.

\section{Ethical approval and consent to participate}

The cadaver belonged to the Department of Anatomical Dissection and Donation, Medical University of Lodz.

\section{RESULTS}

In all the specimens, both IPAs were present. Based on the point of branching, six types of IPA could be identified:

- type 1 - the RIPA and the LIPA originate from the AA (Fig. 1). This type occurred in 14 cadavers;

- type 2 - the RIPA and the LIPA originate from the CT (Fig. 2). This type was observed in 12 cadavers;

- type 3 - the RIPA and the LIPA originate from the left gastric artery (LGA) (Fig. 3). In this type the CT was absent. This type occurred in 3 cadavers;

- type 4 - this type was divided into two subtypes $(A, B)$ :

- $A$ - the LIPA originates from the $A A$, and the RIPA originates from the CT (Fig. 4). This type occurred in 9 cadavers,

- $B$ - the RIPA originates from the AA, and the LIPA originates from the CT (Fig. 5). This type occurred in 6 cadavers;

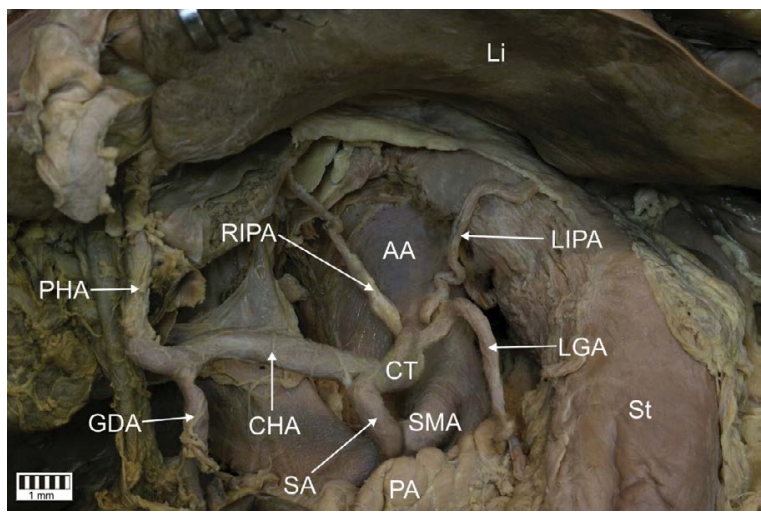

Figure 2. Type 2 - the RIPA and LIPA originate from the coeliac trunk. PHA — proper hepatic artery; GDA — gastro-duodenal artery; RIPA — right inferior phrenic artery; CHA — common hepatic artery; LGA left gastric artery; SA — splenic artery; LIPA — left inferior phrenic artery; CT — coeliac trunk; SMA — superior mesentery artery; St stomach; Li — liver; AA — abdominal aorta; PA — pancreas.

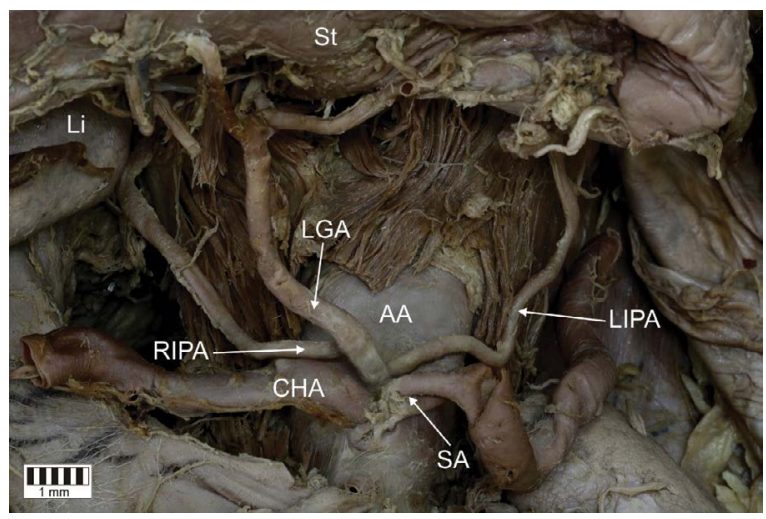

Figure 3. Type 3 - the RIPA and LIPA originate from the left gastric artery. RIPA — right inferior phrenic artery; CHA — common hepatic artery; LGA — left gastric artery; SA — splenic artery; LIPA — left inferior phrenic artery; St — stomach; Li — liver; AA — abdominal aorta.

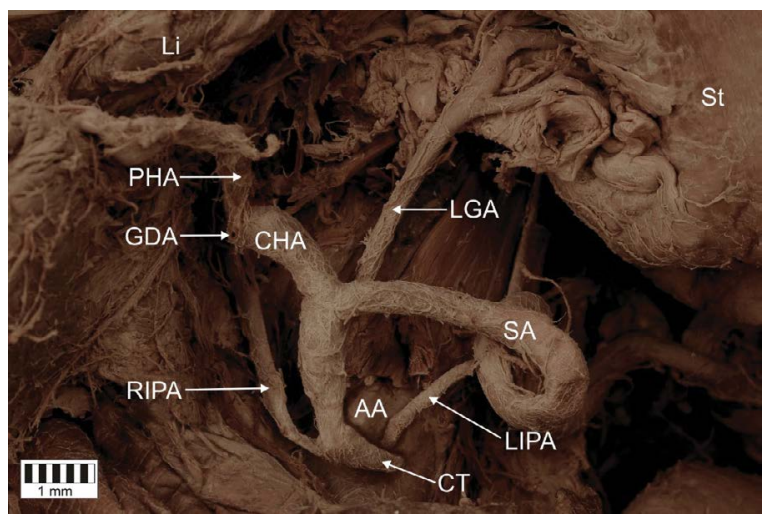

Figure 4. Type $4 A$ - the LIPA originate from the abdominal aorta, and the RIPA originate from the coeliac trunk. PHA - proper hepatic artery; GDA — gastro-duodenal artery; RIPA — right inferior phrenic artery; CHA — common hepatic artery; LGA — left gastric artery; SA — splenic artery; LIPA — left inferior phrenic artery; CT coeliac trunk; St — stomach; Li — liver; AA — abdominal aorta. 


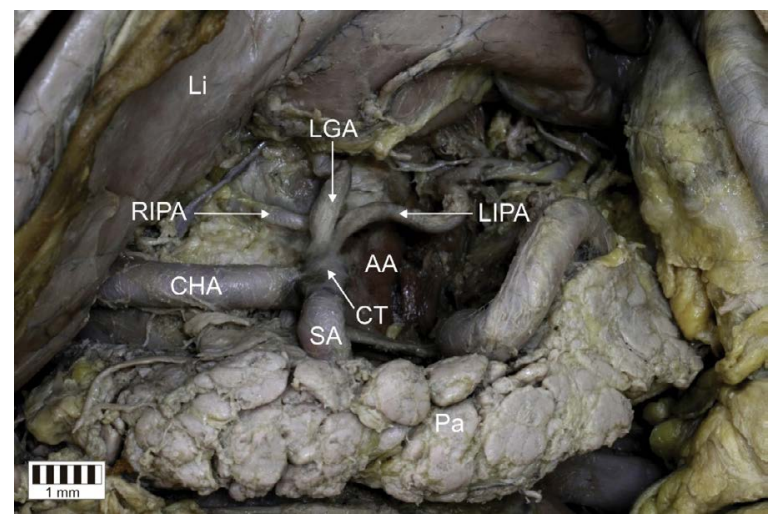

Figure 5. Type $4 B$ - the RIPA originate from the abdominal aorta, and the LIPA originate from the coeliac trunk. RIPA — right inferior phrenic artery; CHA — common hepatic artery; LGA — left gastric artery; SA — splenic artery; LIPA — left inferior phrenic artery; CT — coeliac trunk; $\mathrm{Li}$ - liver; $\mathrm{AA}$ — abdominal aorta; $\mathrm{Pa}$ — pancreas.

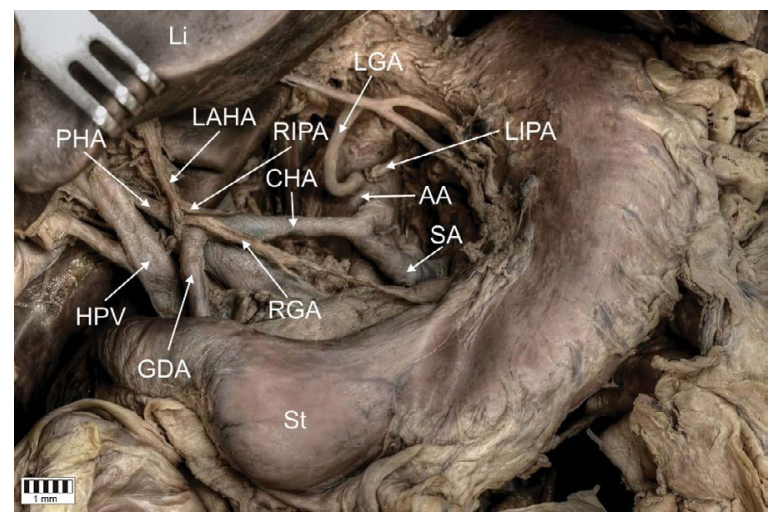

Figure 6. Type 5 - the LIPA originate from the abdominal aorta, and on the right side common trunk for the left accessory hepatic artery and RIPA originate from the abdominal aorta. PHA - proper hepatic artery; GDA - gastro-duodenal artery; RIPA — right inferior phrenic artery; CHA - common hepatic artery; LGA - left gastric artery; SA — splenic artery; LIPA — left inferior phrenic artery; St — stomach; Li — liver; AA — abdominal aorta; LAHA — left accessory hepatic artery; HPV — hepatic portal vein; RGA — right gastric artery.

- type 5 - the LIPA originates from the AA and the RIPA originates from the accessory hepatic artery

(Fig. 6). This type occurred in one cadaver;

- type 6 - the RIPA and the LIPA form a common trunk which originates from the AA (Fig. 7). This type occurred in 3 cadavers.

In Figure 8 we have presented all the types we established in the form of diagrams.

Table 1 presents the origin of LIPA and RIPA according to given type. In almost all types, the LIPA and RIPA are single arteries and have different origins. However, both IPAs originate from the $\mathrm{CT}$ by a short common trunk in type 6.

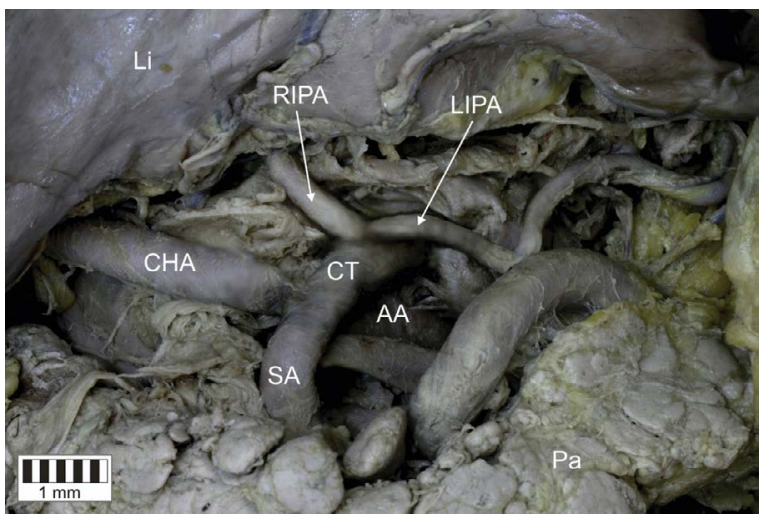

Figure 7. Type 6 - the common trunk for the RIPA and LIPA, which originate from the abdominal aorta. RIPA — right inferior phrenic artery; CHA — common hepatic artery; SA — splenic artery; LIPA — left inferior phrenic artery; Li — liver; AA — abdominal aorta, $\mathrm{Pa}$ - pancreas.

Table 1. Comparison of particular types of left inferior phrenic artery (LIPA) and the right inferior phrenic artery (RIPA) origin

\begin{tabular}{lcc}
\hline & LIPA & RIPA \\
\hline Type 1 & AA & AA \\
Type2 & CT & CT \\
Type 3 & LGA & LGA \\
Type 4A & AA & CT \\
Type 4B & CT & AA \\
Type 5 & AA & AHA \\
Type 6 & CT & \\
\hline
\end{tabular}

AA — abdominal aorta; AHA — accessory hepatic artery; CT — coeliac trunk; LGA left gastric artery

Table 2. Comparison of types according to sex (number and \% for each gender)

\begin{tabular}{lcc}
\hline & Men & Women \\
\hline Type 1 & $5(35.71)$ & $9(26.47)$ \\
Type 2 & $5(35.71)$ & $7(20.59)$ \\
Type 3 & $1(7.14)$ & $2(5.88)$ \\
Type 4A & $3(21.43)$ & $6(17.65)$ \\
Type 4B & - & $6(17.65)$ \\
Type 5 & - & $1(2.94)$ \\
Type 6 & - & $3(8.82)$ \\
\hline
\end{tabular}

Table 2 presents the distribution of IPA types according to sex. Although no significant difference in distribution was observed $(p=0.4916)$, it is important to note that types $4 B, 5$ and 6 did not occur in men.

Table 3 presents diameters of the LIPA and the RIPA according to sex. In general, no significant difference 


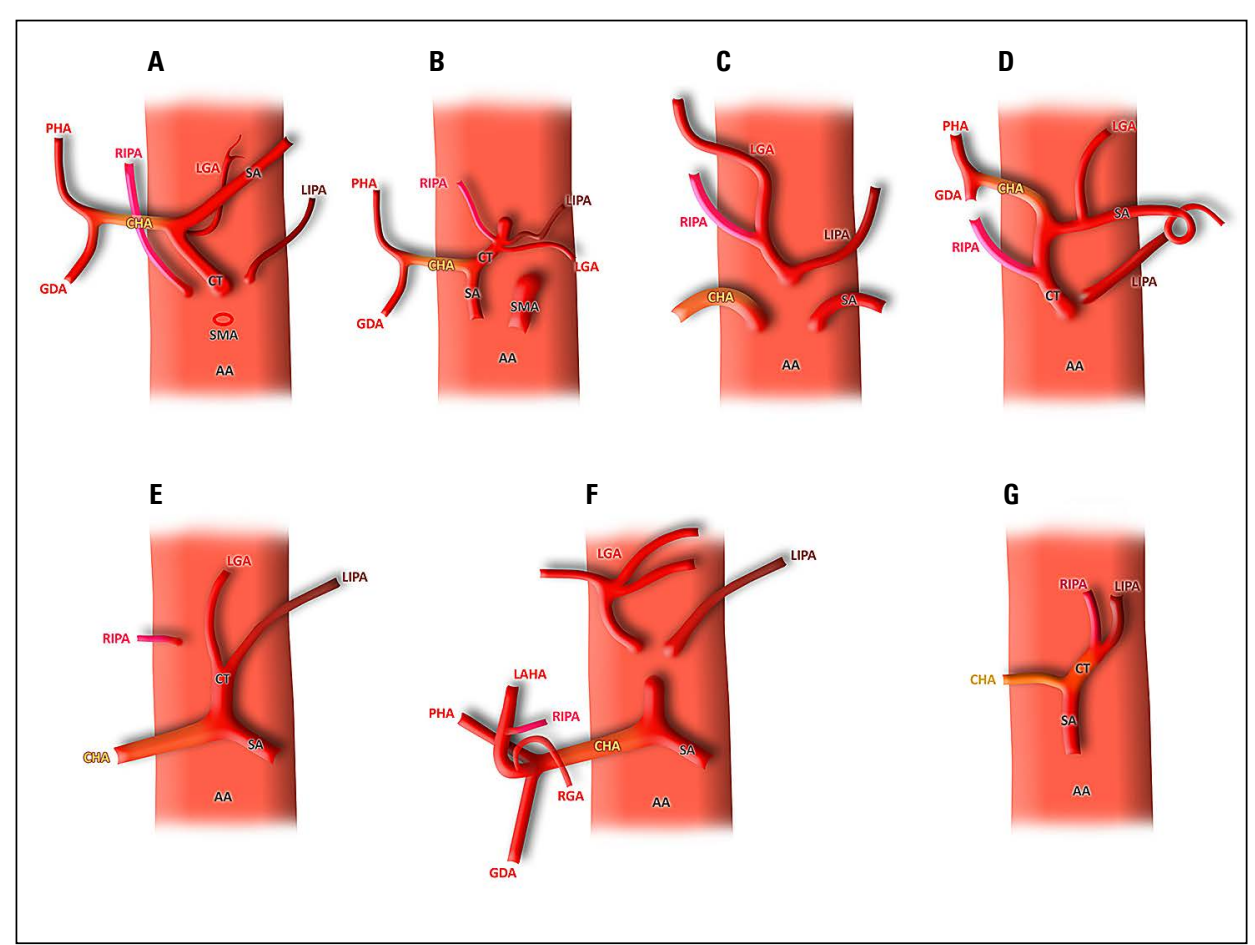

Figure 8. Scheme presents all types of left inferior phrenic artery (LIPA) and the right inferior phrenic artery (RIPA) origins; A. Type 1; B. Type 2; C. Type 3; D. Type 4A; E. Type 4B; F. Type 5; G. Type 6.

Table 3. Comparison of left inferior phrenic artery (LIPA) and the right inferior phrenic artery (RIPA) diameter according to type and sex

\begin{tabular}{|c|c|c|c|c|c|}
\hline & & \multicolumn{2}{|c|}{ LIPA [mm] } & \multicolumn{2}{|c|}{ RIPA [mm] } \\
\hline & & Men & Women & Men & Women \\
\hline \multirow[t]{3}{*}{ Type 1} & Maximum & 3.07 & 3.19 & 2.90 & 3.20 \\
\hline & Minimum & 2.54 & 1.66 & 2.21 & 2.01 \\
\hline & Average & 2.80 & 2.45 & 2.59 & 2.50 \\
\hline \multirow[t]{3}{*}{ Type 2} & Maximum & 3.11 & 2.14 & 3.57 & 2.74 \\
\hline & Minimum & 1.86 & 1.88 & 2.46 & 1.69 \\
\hline & Average & 2.36 & 2.01 & 3.04 & 2.25 \\
\hline \multirow[t]{3}{*}{ Type 3} & Maximum & 2.61 & 2.21 & 3.19 & 2.41 \\
\hline & Minimum & 2.31 & 2.21 & 2.85 & 2.41 \\
\hline & Average & 2.46 & 2.21 & 3.02 & 2.41 \\
\hline \multirow[t]{3}{*}{ Type 4A } & Maximum & 3.55 & 3.49 & 4.03 & 3.11 \\
\hline & Minimum & 2.44 & 2.61 & 2.74 & 2.95 \\
\hline & Average & 3.02 & 3.05 & 3.44 & 3.01 \\
\hline \multirow[t]{3}{*}{ Type 4B } & Maximum & - & 2.50 & - & 2.70 \\
\hline & Minimum & - & 1.98 & - & 2.04 \\
\hline & Average & - & 2.24 & - & 2.55 \\
\hline \multirow[t]{3}{*}{ Type 5} & Maximum & - & 2.56 & - & 2.86 \\
\hline & Minimum & - & 2.56 & - & 2.86 \\
\hline & Average & - & 2.56 & - & 2.86 \\
\hline \multirow[t]{3}{*}{ Type 6} & Maximum & - & 2.28 & - & 2.28 \\
\hline & Minimum & - & 2.02 & & 2.02 \\
\hline & Average & - & 2.15 & & 2.15 \\
\hline
\end{tabular}

in mean LIPA or RIPA diameter was observed between sexes: LIPA, $2.46 \pm 0.44 \mathrm{~mm}$ for women compared to $2.66 \pm 0.47 \mathrm{~mm}$ for men $(p=0.1846) ; R I P A, 2.59 \pm$ $\pm 0.46 \mathrm{~mm}$ for women compared to $2.73 \pm 0.63 \mathrm{~mm}$ for men $(p=0.6830)$.

Regarding the types, LIPA diameter was significantly greater in type 4A than in types 1 and $4 B$ $(p=0.0045)$. For the RIPA, the differences were not significant.

\section{DISCUSSION}

Vascular abnormalities are very common in the abdomen; the area undergoes many modifications during the formation of the adult vascular system. In addition, it is possible for multiple arterial variants to develop within a single person [14]. The type of IPA varies depending on the occurrence of other abdominal vascular variations; in particular, different origins of both LIPA and RIPA may be observed in the presence of variations of the CT $[19,22,26,41]$.

This correlation can be explained by the embryological development of the CT [4, 10, 11, 24, 27, 32, 37]. The aorta has posterior, lateral and abdominal branches, which form the CT and the longitudinal anastomoses between them. The growth of the lon- 
gitudinal anastomoses and regression of the abdominal branches affects the formation of various types of the CT division. The IPA primarily arises from the abdominal roots of the aorta and most likely from the same level as the $\mathrm{CT}[12,33,35,40]$.

For example, Olewnik et al. proposes that the variant of the $C T$ branching into the common hepatic artery, the LGA, splenic artery and LIPA should be called the coeliacophrenic trunk. This type was observed in $14.5 \%$ of a group of 40 cadavers, i.e. the second most common type [2, 23].

We propose the following 6 -fold classification of IPA origin based on our findings. In type 1, the lower diaphragmatic arteries are branches of the AA above the CT. Previous studies have found this type to occur in over $50 \%$ of preparations [29], while it was observed in about $29.12 \%$ of cases in the present study.

Type 2 is characterised by both lower diaphragmatic arteries forming separate branches arising from the $\mathrm{CT}$. It was found to be the most common type by Basile et al. (41\% of preparations) [3]; however, it was present in about $24.96 \%$ of cadavers in the present study.

In type 3, the RIPA and the LIPA arise from the LGA. It was observed in $6.24 \%$ of the cadavers, which was much less common than recorded by other authors, e.g. Loukas et al. [18] note it was present in about $2 \%$ of specimens.

In type 4, one IPA originates from the $\mathrm{CT}$ and the other from the AA. This type was divided into two subtypes. Subtype 4A, where the LIPA originates from the $A A$ and the RIPA originates from the $C T$, was observed in about $18.72 \%$ of the cadavers. Subtype $4 B$, in which RIPA originates at the AA and the LIPA at the CT, occurred in $12.48 \%$ of the tested specimens. As these subtypes have not been discussed in any previous study, it is not possible to make any comparisons regarding the frequency of occurrence.

In type 5, the LIPA runs directly from the AA, while both RIPA and left accessory hepatic artery originate from the AA. this is a comparatively rare type, occurring in only $2.08 \%$ of the examined cadavers. As with type 4, this type has not been discussed in any other previous study.

In our final proposed type, type 6 , the LIPA and RIPA form a common trunk arising from the AA. This type was observed in only $6.24 \%$ of the studied cadavers; however, Basile et al. [3] reported it in about $21 \%$ of specimens.
Table 4. Overview of previous studies which investigated the origin of inferior phrenic artery types and the present study

\begin{tabular}{|c|c|c|c|c|c|c|c|}
\hline & \multirow{2}{*}{$\begin{array}{c}\text { Type } \\
1\end{array}$} & \multirow{2}{*}{$\begin{array}{c}\text { Type } \\
2\end{array}$} & \multirow{2}{*}{$\begin{array}{c}\text { Type } \\
3\end{array}$} & \multicolumn{2}{|c|}{ Type 4} & \multirow{2}{*}{$\begin{array}{c}\text { Type } \\
5\end{array}$} & \multirow{2}{*}{$\begin{array}{c}\text { Type } \\
6\end{array}$} \\
\hline & & & & A & B & & \\
\hline $\begin{array}{l}\text { Adachi } \\
\text { et al. } 1928\end{array}$ & 11 & 6 & 1 & - & - & - & - \\
\hline $\begin{array}{l}\text { Pick and Anson } \\
\text { et al. } 1941\end{array}$ & 37 & 26 & 4 & - & - & - & - \\
\hline Greig et al. 1951 & 77 & 52 & 3 & - & - & - & - \\
\hline Kahn et al. 1967 & 13 & - & - & - & - & - & - \\
\hline $\begin{array}{l}\text { Lippert and } \\
\text { Pabst et al. } 1985\end{array}$ & $18 \%$ & $14 \%$ & $1 \%$ & - & - & - & - \\
\hline Piao et al. 1998 & 6 & 4 & - & - & - & - & - \\
\hline $\begin{array}{l}\text { Loukas et al. } \\
2005\end{array}$ & 22 & 12 & - & - & - & - & - \\
\hline $\begin{array}{l}\text { Gwon et al, } \\
2007\end{array}$ & - & - & - & - & - & - & - \\
\hline $\begin{array}{l}\text { Basile et al. } \\
2008\end{array}$ & 42 & 32 & - & - & - & - & - \\
\hline $\begin{array}{l}\text { Ozbulbul et al. } \\
2011\end{array}$ & 16 & 18 & - & - & - & - & - \\
\hline Our study & 14 & 12 & 3 & 9 & 6 & 1 & 3 \\
\hline
\end{tabular}

Our proposed type $4(A, B)$, type 5 and type 6 and their LIPA and the RIPA origins' configurations have not been reported in previous studies (Table 4).

Inferior phrenic arteries are one of the most important collateral arteries that provide blood to hepatocellular carcinoma located in the peripheral segments and bare area of the liver $[3,15]$.

One of the priorities for successful treatment of hepatocellular carcinoma is the complete embolisation of the blood supply. To ensure this, and prevent complications due to embolisation of the non-targeted branches, computed tomography angiography identification of the arteries supplying the tumour is an important clinical step $[8,21,25]$. In addition to RIPA embolisation, gastroesophageal complications may occur if the ascending branch of the LIPA originates from the RIPA $[16,28]$. The same type should also be kept in mind if an IPA embolisation is planned in patients with upper gastroesophageal bleeding $[5,38]$.

\section{Limitations of the study}

The present study does have some limitations. Being based on several morphological details, such as type of the origin, the classification is of quite a heterogeneous nature; as this is only an anatomical study, a spectrum 
of variation could be presented, and further studies should examine the potential value of angiography or CT for this purpose. Nonetheless, our findings help raise awareness of "what and where" to look for, and offers a uniform classification and terminology which can be used as a foundation for communication with surgeons, particularly those harvesting tendons for transplants. Another limitation is the small research sample (48); however, this group is nevertheless larger than used in similar studies of this type.

\section{CONCLUSIONS}

Our work adds a new perspective to our understanding of IPA anatomy by measurements its diameter. Our results indicate that while no significant differences can be found in RIPA diameter, LIPA diameter varies significantly. No significant differences in RIPA or LIPA diameter were found according to sex.

We therefore propose a 6-fold classification created by analysing the departure of the RIPA and LIPA. In contrast to previous studies, we considered the arteries as a pair and not as separate vessels.

\section{Conflict of interest: None declared}

\section{REFERENCES}

1. Anatomy Atlases Illustrated Encyclopedia of Human Anatomic Variation - Anatomical Variation Radiology Anatomy. https://www.anatomyatlases.org/AnatomicVariants/ AnatomyHP.shtml.

2. Aslaner R, Pekcevik Y, Sahin $\mathrm{H}$, et al. Variations in the origin of inferior phrenic arteries and their relationship to celiac axis variations on CT angiography. Korean J Radiol. 2017; 18(2): 336-344, doi: 10.3348/kjr.2017.18.2.336, indexed in Pubmed: 28246513.

3. Basile A, Tsetis D, Montineri A, et al. MDCT anatomic assessment of right inferior phrenic artery origin related to potential supply to hepatocellular carcinoma and its embolization. Cardiovasc Intervent Radiol. 2008; 31(2): 349-358, doi: 10.1007/s00270-007-9236-x, indexed in Pubmed: 18071790.

4. Book - Manual of Human Embryology II - Embryology. https://embryology.med.unsw.edu.au/embryology/index. php/Book_-_Manual_of_Human_Embryology_II\#Chapter_XIX._By_W_Felix (Accessed 24 Mar 2020).

5. Dong II, Ko GYG, Yoon HK, et al. Inferior phrenic artery: anatomy, variations, pathologic conditions, and interventional management. Radiographics. 2007; 27(3): 687-705, doi: 10.1148/rg.273065036, indexed in Pubmed: 17495287.

6. Exhibit E. Inferior Phrenic Artery: Anatomy, Variations, Pathologic Conditions, and Interventional. 2007: 687-706.

7. Goss C. Blood supply and anatomy of the upper abdominal organs with a descriptive atlas. By N. A. Michels. xiv + 581 pages, 172 figures. $\$ 24.00$. J. B. Lippincott Company,
Philadelphia, 1955. The Anatomical Record. 1960; 137(2): 153-154, doi: 10.1002/ar.1091370211.

8. Greig HW, Anson BJ, Coleman SS. The inferior phrenic artery; types of origin in 850 body-halves and diaphragmatic relationship. Q Bull Northwest Univ Med Sch. 1951; 25(4): 345-350, indexed in Pubmed: 14892223.

9. Gürses IA, Gayretli Ö, Kale A, et al. Inferior phrenic arteries and their branches, their anatomy and possible clinical importance: an experimental cadaver study. Balkan Med J. 2015; 32(2): 189-195, doi: 10.5152/balkanmedj.2015.150052, indexed in Pubmed: 26167344.

10. Hemamalini A. Variations in the branching pattern of the celiac trunk and its clinical significance. Anat Cell Biol. 2018; 51(3): 143-149, doi: 10.5115/acb.2018.51.3.143, indexed in Pubmed: 30310705.

11. Huang Y, Mu GC, Qin XG, et al. Study of celiac artery variations and related surgical techniques in gastric cancer. World J Gastroenterol. 2015; 21(22): 6944-6951, doi: 10.3748/wjg.v21.i22.6944, indexed in Pubmed: 26078572 .

12. lezzi R, Cotroneo AR, Giancristofaro D, et al. Multidetector-row $C T$ angiographic imaging of the celiac trunk: anatomy and normal variants. Surg Radiol Anat. 2008; 30(4): 303-310, doi: 10.1007/s00276-008-0324-7, indexed in Pubmed: 18286222.

13. Isogai S, Horiguchi M, Hitomi J. The para-aortic ridge plays a key role in the formation of the renal, adrenal and gonadal vascular systems. J Anat. 2010; 216(6): 656-670, doi: 10.1111/j.1469-7580.2010.01230.x, indexed in Pubmed: 20579173.

14. Kahn C, MacNeil M, Fanola C, et al. Complex arterial patterning in an anatomical donor. Trans Res Anat. 2018; 12: 11-19, doi: 10.1016/j.tria.2018.06.001.

15. Kimura S, Okazaki M, Higashihara $\mathrm{H}$, et al. Analysis of the origin of the right inferior phrenic artery in 178 patients with hepatocellular carcinoma treated by chemoembolization via the right inferior phrenic artery. Acta Radiol. 2007; 48(7): 728-733, doi: 10.1080/02841850701376334, indexed in Pubmed: 17729002.

16. Lee DHo, Chung JW, Kim HC, et al. Development of diaphragmatic weakness after transcatheter arterial chemoembolization of the right inferior phrenic artery: frequency and determinant factors. J Vasc Interv Radiol. 2009; 20(4): 484-489, doi: 10.1016/j.jvir.2008.11.023, indexed in Pubmed: 19157895.

17. Lee JW, Kim S, Kim CW, et al. Massive hemoperitoneum due to ruptured inferior phrenic artery pseudoaneurysm after blunt trauma. Emerg Radiol. 2006; 13(3): 147-149, doi: 10.1007/s10140-006-0524-6, indexed in Pubmed: 17039340 .

18. Loukas M, Hullett J, Wagner T. Clinical anatomy of the inferior phrenic artery. Clin Anat. 2005; 18(5): 357-365, doi: 10.1002/ca.20112, indexed in Pubmed: 15971218.

19. Merklin RJ, Michels NA. The variant renal and suprarenal blood supply with data on the inferior phrenic, ureteral and gonadal arteries: a statistical analysis based on 185 dissections and review of the literature. J Int Coll Surg. 1958; 29(1 Pt 1): 41-76, indexed in Pubmed: 13502578.

20. Miclaus GD, Matusz $P$, Loukas $M$, et al. Rare case of the trunk of the inferior phrenic arteries originating from a common stem with a superior additional left renal 
artery from the abdominal aorta. Clin Anat. 2012; 25(8): 979-982, doi: 10.1002/ca.22161, indexed in Pubmed: 22949218

21. Miyayama S, Yamashiro M, Yoshie $Y$, et al. Inferior phrenic arteries: angiographic anatomy, variations, and catheterization techniques for transcatheter arterial chemoembolization. Jpn J Radiol. 2010; 28(7): 502-511, doi: 10.1007/ s11604-010-0456-7, indexed in Pubmed: 20799015.

22. Mu GC, Huang Y, Liu ZM, et al. Clinical research in individual information of celiac artery $\mathrm{CT}$ imaging and gastric cancer surgery. Clin Transl Oncol. 2013; 15(10): 774-779, doi: 10.1007/s12094-013-1002-8, indexed in Pubmed: 23359186.

23. Olewnik $Ł$, Wysiadecki G, Polguj $M$, et al. Types of coeliac trunk branching including accessory hepatic arteries: a new point of view based on cadaveric study. Folia Morphol. 2017; 76(4): 660-667, doi: 10.5603/FM.a2017.0053, indexed in Pubmed: 28612916.

24. Osman A, Abdrabou A. Celiac trunk and hepatic artery variants: A retrospective preliminary MSCT report among Egyptian patients. Egyptian J Radiol Nuclear Med. 2016; 47(4): 1451-1458, doi: 10.1016/j.ejrnm.2016.09.011.

25. Ozbülbül NI, Yurdakul M, Tola M. Does the right inferior phrenic artery have a supplying role in liver cirrhosis without hepatocellular carcinoma? A 64-slice CT study. Diagn Interv Radiol. 2011; 17(3): 239-242, doi: 10.4261/13053825.DIR.3395-10.1, indexed in Pubmed: 20690077.

26. Ozbülbül NI. CT angiography of the celiac trunk: anatomy, variants and pathologic findings. Diagn Interv Radiol 2011; 17(2): 150-157, doi: 10.4261/1305-3825.DIR.328310.1, indexed in Pubmed: 20690078.

27. Panagouli $E$, Venieratos $D$, Lolis $E$, et al. Variations in the anatomy of the celiac trunk: A systematic review and clinical implications. Ann Anat. 2013; 195(6): 501-511, doi: 10.1016/j. aanat.2013.06.003, indexed in Pubmed: 23972701.

28. Petrella $S$, Rodriguez $C$, Sgrott $E$, et al. Origin of Inferior Phrenic Arteries in the Celiac Trunk. Int J Morphol. 2006; 24(2), doi: 10.4067/s0717-95022006000300024.

29. Piao DX, Ohtsuka A, Murakami T. Typology of abdominal arteries, with special reference to inferior phrenic arteries and their esophageal branches. Acta Med Okayama. 1998; 52(4): 189-196, doi: 10.18926/AMO/31299, indexed in Pubmed: 9781269.

30. Pick J, Anson B. The inferior phrenic artery: Origin and suprarenal branches. Anat Record. 1940; 78(4): 413-427, doi: 10.1002/ar.1090780402.

31. Pulakunta T, Potu B, Gorantla V, et al. The origin of the inferior phrenic artery: a study in 32 South Indian cadavers with a review of the literature. Jornal Vascular
Brasileiro. 2007; 6(3): 225-230, doi: 10.1590/s167754492007000300005.

32. Santos PV, Barbosa AB, Targino VA, et al. Anatomical variations of the celiac trunk: a systematic review. Arq Bras Cir Dig. 2018; 31(4): e1403, doi: 10.1590/0102672020180001e1403, indexed in Pubmed: 30539978.

33. Sheybanifar M. A variation of the inferior phrenic arteries: a case report. Hormozgan Med J. 2019; 23(3), doi: 10.5812/hmj.86605.

34. Shin SW, Do YS, Choo SW, et al. Diaphragmatic weakness after transcatheter arterial chemoembolization of inferior phrenic artery for treatment of hepatocellular carcinoma. Radiology. 2006; 241(2): 581-588, doi: 10.1148/radiol.2412051209, indexed in Pubmed: 17005772.

35. So YH, Chung JW, Yin Y, et al. The right inferior phrenic artery: origin and proximal anatomy on digital subtraction angiography and thin-section helical computed tomography. J Vasc Interv Radiol. 2009; 20(9): 1164-1171, doi: 10.1016/j.jvir.2009.05.036, indexed in Pubmed: 19631560.

36. Standring S, Ellis H, Healy J. et al. Gray's anatomy. The Anatomical Basis of Clinical Medicine. Elsevier Health Sciences, UK 2008.

37. Sureka B, Mittal MK, Mittal A, et al. Variations of celiac axis, common hepatic artery and its branches in 600 patients. Indian J Radiol Imaging. 2013; 23(3): 223-233, doi: 10.4103/0971-3026.120273, indexed in Pubmed: 24347852.

38. Takanami I. Massive haemoptysis due to chronic pancreatitis: control with inferior phrenic artery embolization. Eur J Cardio-Thoracic Surg. 2000; 18(1): 120-122, doi: 10.1016/s1010-7940(00)00468-1.

39. Tanaka R, Ibukuro K, Akita K. The left inferior phrenic artery arising from left hepatic artery or left gastric artery: radiological and anatomical correlation in clinical cases and cadaver dissection. Abdom Imaging. 2008; 33(3): 328-333, doi: 10.1007/s00261-007-9249-6, indexed in Pubmed: 17522754.

40. Winston $C B$, Lee $N A$, Jarnagin $W R$, et al. CT angiography for delineation of celiac and superior mesenteric artery variants in patients undergoing hepatobiliary and pancreatic surgery. Am J Roentgenol. 2007; 189(1): W13-W19, doi: 10.2214/AJR.04.1374, indexed in Pubmed: 17579128.

41. Zeng R, Yao Z, Chen Y, et al. Variant arterial supply to the lesser curvature of the stomach and duodenum from double inferior phrenic arteries. Surg Radiol Anat. 2015; 37(7): 867-869, doi: 10.1007/s00276-014-1392-5, indexed in Pubmed: 25380829. 